\title{
Expanding the definition of a positive family history for early-onset coronary heart disease
}

\author{
Maren T. Scheuner, MD, MPH ${ }^{1,2}$, William C. Whitworth, MPH ${ }^{1}$, Henraya McGruder, PhD, MS ${ }^{3}$,
} Paula W. Yoon, ScD, $M P H^{1}$, and Muin J. Khoury, $M D, P h D^{1}$

\begin{abstract}
Purpose: Assessing familial risk for early-onset coronary heart disease (CHD) is typically limited to first-degree relatives with early-onset CHD. To evaluate the impact of additional family history, we examined the associations between various family history definitions and early-onset CHD. Methods: By using the national HealthStyles 2003 survey data, we assessed associations between self-reported family history and personal history of early-onset CHD (diagnosed at or before age 60 years), adjusting for demographics, hypercholesterolemia, hypertension, and obesity. Results: Of 4035 respondents, $60 \%$ were female and $72 \%$ were white, with a mean age of 48.8 years; 4.4\% had early-onset CHD. In addition to having at least one first-degree relative with early-onset CHD, other significant associations included having at least one first-degree relative with late-onset CHD, at least one second-degree relative with early-onset CHD, and two or more affected second-degree relatives regardless of age of onset of CHD. Early-onset stroke in at least one first-degree relative and, in women, having at least one first-degree relative with diabetes were also significantly associated with early-onset CHD. Conclusions: Family history beyond early-onset CHD in first-degree relatives is significantly associated with prevalent CHD diagnosed at or before age 60 years. Genet Med 2006:8(8):491-501.
\end{abstract}

Coronary heart disease (CHD) is the leading cause of premature death and disability in the United States and other developed countries. ${ }^{1}$ Several risk factors are known to contribute to CHD. Global risk assessment is an approach to CHD prevention that estimates the absolute risk based on the summation of risks contributed by each risk factor. ${ }^{2}$ Although not all risk factors are modifiable, all can contribute to the risk assessment, and the intensity of risk factor management can be adjusted according to the severity of the overall risk.

Family history is an important and independent CHD risk factor, especially for early-onset disease. Many studies have found a two- to threefold increase in CHD given a first-degree relative with $\mathrm{CHD},{ }^{3-6}$ and the strength of this association increases as the number of affected first-degree relatives increases ${ }^{7,8}$ and with younger ages of CHD onset in relatives. ${ }^{7-10}$ Less is known about the effects of later-onset CHD in relatives, second-degree relatives with CHD, or the presence of stroke and diabetes among relatives. Furthermore, few studies have assessed the impact of the type of relative affected with CHD

\footnotetext{
From the ${ }^{I}$ Office of Genomics and Disease Prevention, Centers for Disease Control and Prevention, Atlanta, Georgia; ${ }^{2}$ RAND Corporation, Santa Monica, California; and ${ }^{3}$ Division of Heart Disease and Stroke Prevention, National Center for Chronic Disease Prevention and Health Promotion, Coordinating Center for Health Promotion, Centers for Disease Control and Prevention, Atlanta, Georgia.

Maren T. Scheuner, MD, MPH, RAND Corporation, 1776 Main Street, P.O. Box 2138, Santa Monica, CA 90407-2138.
}

Submitted for publication March 2, 2006.

Accepted for publication May 15, 2006.

DOI: 10.1097/01.gim.0000232582.91028.03 (e.g., parent or sibling) or the lineage of affected relatives (i.e., maternal or paternal) on CHD risk.

The Framingham Risk Score is a common global risk assessment method for CHD that is used to guide preventive interventions. Age is a prominent determinant of the Framingham risk estimate, and family history is not included as a risk factor. ${ }^{11}$ Therefore, the Framingham score may underestimate CHD risk for individuals with family history, particularly at young ages when prevention could have substantial benefits given the risk for early-onset disease.

The National Cholesterol Education Program Adult Treatment Panel III (NCEP ATPIII) guidelines provide recommendations for CHD prevention, focusing on lipid lowering. The number of risk factors an individual has determines the lowdensity lipoprotein cholesterol goal. Family history is included as a risk factor, but is limited to premature CHD (age of onset $<55$ years for men and $<65$ years for women) in first-degree relatives. ${ }^{12}$ If family history characteristics beyond premature CHD in first-degree relatives also increase CHD risk, the NCEP guidelines might underestimate CHD risk and the need for lipid-lowering therapies or other preventive interventions for individuals with such histories.

The goal of this study was further characterization of family history as a risk factor for CHD diagnosed at or before age 60 years (early onset) by a comprehensive assessment of associations between self-reports of prevalent early-onset CHD and various definitions of family history of $\mathrm{CHD}$, stroke, and diabetes that include age at onset, number of affected relatives, degree of relationship, type, and lineage of affected relatives. 


\section{MATERIALS AND METHODS}

\section{Subjects}

The HealthStyles 2003 survey was the source of data for this cross-sectional study. HealthStyles is an annual mail survey of health-related attitudes and behaviors among the U.S. adult population. ${ }^{13}$ It is a subset of a two-part consumer survey designed and conducted by Synovate, Inc. (Arlington Heights, IL), a marketing firm that annually recruits approximately 600,000 potential respondents. HealthStyles is used for healthcommunications planning by organizations (including the U.S. Centers for Disease Control and Prevention) that influence the design and administration of the questionnaire. In 2003, a stratified random sample of 5845 adults was selected, of whom 4035 (69\%) agreed to participate. Questions about personal and family history of $\mathrm{CHD}$, stroke, and diabetes were included in the survey. The Centers for Disease Control and Prevention Institutional Review Board approved this study.

\section{Personal and family history assessment}

Respondents provided information about their age, sex, ethnicity/race, education, income, marital status, and medical history. Personal history of CHD was considered present if a respondent reported that a doctor had diagnosed CHD, such as myocardial infarction (MI), coronary bypass graft surgery, or angioplasty. Angina was not included in the definition. Personal history of stroke was considered present if a respondent reported that a doctor had diagnosed stroke or transient ischemic attack (TIA). For both CHD and stroke, respondents indicated whether their diagnosis was made at or before age 60 years (early onset) or after age 60 years (late onset). We chose the age of 60 years because this is often used as a definition of premature CHD in epidemiologic studies of cardiovascular disease, and it is similar to the age cutoff used by the NCEP ATPIII guidelines, which describe family history of premature CHD as age of onset less than 55 years for men and less than 65 years for women in a first-degree relative. ${ }^{12}$ Respondents were considered to have diabetes or to be obese if they reported having either condition currently or in the past year. Hypercholesterolemia was coded as present if respondents had ever been told by a health professional that they had high blood cholesterol or to take medication for high cholesterol. Hypertension was considered present if respondents reported ever being told on two or more office visits that they had high blood pressure or if they were ever prescribed medication to lower their blood pressure. Hypertension or diabetes diagnosed only during pregnancy was excluded.

Family history was obtained from respondents by asking about CHD or stroke/TIA diagnoses occurring at or before age 60 years (early onset) or after age 60 years (late onset) in first-degree relatives (mother, father, and siblings) and second-degree relatives (aunts, uncles, and grandparents). Response options included "yes," "no," and "don't know." Respondents also indicated if they had zero, one, or two or more siblings or second-degree relatives diagnosed with CHD or stroke/TIA. Family history of diabetes was positive if any first-degree relative had diabetes or high blood glucose levels, excluding pregnancy-related diagnoses. Response options were "yes," "no," and "don't know." Diabetes type and age at onset were not ascertained.

\section{Statistical analyses}

We used descriptive statistics to characterize respondents, chisquare tests to assess differences in proportions, and the Student $t$ test to assess differences in means. Odds ratios (ORs) were calculated to assess the associations of individual family history characteristics with self-reported early-onset CHD compared with no $\mathrm{CHD}$, with adjustment for age, sex, ethnicity/race, marital status, education, income, self-reported obesity, hypercholesterolemia, and hypertension. These individual family history characteristics describe differences in age at onset of CHD (early or late), number of affected relatives (only one or two or more), type of relative with CHD (parent or sibling), or lineage of affected relatives (nuclear, maternal, or paternal). Given the small number of observations for many of these individual family history characteristics, we could not assess associations between combinations of these characteristics and CHD. Because previous reports have found sex-specific effects on the association between family history and $\mathrm{CHD},{ }^{14-17}$ the Breslow Day test for OR heterogeneity was performed to assess interactions between the various family history definitions and sex. When significant interactions $(P<.05)$ were found, sex-specific associations are reported. Personal histories of stroke or diabetes were not included in the models because these diagnoses are considered CHD risk equivalents by the NCEP ATPIII guidelines. ${ }^{12}$ According to these guidelines, because the magnitude of risk for CHD is so great for individuals with diabetes or stroke, regardless of the presence of other risk factors, the threshold for aggressive preventive intervention is reached and clinicians are advised to approach CHD prevention in these individuals as if $\mathrm{CHD}$ had already been diagnosed. Considering this perspective, we chose not to include these diagnoses in our models, because in practice knowing family history would not be relevant to the risk stratification and resulting preventive recommendations. In addition, because numerous studies have found significant associations between family history of CHD and personal history of stroke, ${ }^{18-23}$ and because family history of diabetes is associated with family history of $\mathrm{CHD},{ }^{24}$ it is unlikely that the overall patterns and strength of associations would change substantially if we included personal history of diabetes and stroke in our models. The 79 individuals with late-onset CHD were excluded from the analyses. "Don't know" responses were considered as "no" responses in the logistic regression models. All statistical analyses were performed using SAS v8.2 (SAS Institute, Cary, NC).

\section{RESULTS}

\section{Respondent characteristics}

There were 4035 respondents, including 178 with early-onset $\mathrm{CHD}, 79$ with late-onset $\mathrm{CHD}$, and 3778 with no personal history of CHD. The characteristics of respondents with early-onset CHD and no CHD are presented in Table 1 . The mean age of respondents with no history of CHD was significantly less than the mean age of respondents with early-onset CHD: 47.5 years (standard 
Table 1

Characteristics of respondents with early-onset coronary heart disease and no coronary heart disease (HealthStyles 2003 Survey of Health-related Attitudes and Behaviors Among the U.S. Adult Population)

\begin{tabular}{|c|c|c|c|}
\hline Characteristic & $\begin{array}{l}\text { Early-onset CHD } \\
\quad(\mathrm{n}=178) \\
\mathrm{n}(\%)\end{array}$ & $\begin{array}{c}\text { No CHD } \\
(\mathrm{n}=3778) \\
\mathrm{n}(\%)\end{array}$ & $P$ values ${ }^{c}$ \\
\hline Female & $81(45.5)$ & $2307(61.1)$ & .002 \\
\hline \multicolumn{4}{|l|}{ Age group $^{b}$} \\
\hline $18-34 y$ & $8(4.5)$ & $692(18.3)$ & .00004 \\
\hline $35-44 y$ & $16(9.0)$ & $28.8(1088)$ & $<.00002$ \\
\hline $45-54$ y & $54(30.3)$ & $956(25.3)$ & .13 \\
\hline $55-64$ y & $62(34.8)$ & $493(13.0)$ & $<.00002$ \\
\hline $65+y$ & $38(21.3)$ & $549(14.5)$ & .2 \\
\hline \multicolumn{4}{|l|}{ Race/ethnicity } \\
\hline White & $127(71.3)$ & $2709(71.7)$ & .91 \\
\hline African American & $26(14.6)$ & $462(12.2)$ & .33 \\
\hline Hispanic & $15(8.4)$ & $428(11.3)$ & .23 \\
\hline Asian & $5(2.8)$ & $132(3.5)$ & .62 \\
\hline Other race/ethnicity & $5(2.8)$ & $47(1.2)$ & .12 \\
\hline $\begin{array}{l}\text { More than high school } \\
\text { education }\end{array}$ & $92(51.7)$ & $2321(61.4)$ & .18 \\
\hline Ever married & $166(93.3)$ & $3268(86.5)$ & .18 \\
\hline Income $>\$ 35,000$ & $71(39.9)$ & $2195(58.1)$ & .00004 \\
\hline Stroke onset $<60$ y & $29(16.3)$ & $87(2.3)$ & $<.00002$ \\
\hline Stroke onset $>60 y$ & $30(16.9)$ & $127(3.4)$ & $<.00002$ \\
\hline Diabetes & $69(38.8)$ & $397(10.5)$ & $<.00002$ \\
\hline Obesity & $52(29.2)$ & $631(16.7)$ & .00032 \\
\hline Hypertension & $124(69.7)$ & $1158(30.7)$ & $<.00002$ \\
\hline Hypercholesterolemia & $130(73.0)$ & $1190(31.5)$ & $<.00002$ \\
\hline
\end{tabular}

CHD, coronary heart disease; early-onset CHD, disease at or before age 60 years.

${ }^{a}$ Corrected $P$ values adjusted for 20 comparisons.

${ }^{b}$ Mean age (standard deviation) for early-onset CHD, 55.8 years (11.1 years) and no CHD, 47.5 years ( 14.1 years) $(P<.0001)$.

deviation 14.1) and 55.8 years (standard deviation 11.1), respectively $(P<.0001)$. There were also significantly fewer women among respondents with early-onset CHD compared with the respondents with no $\mathrm{CHD}$, and respondents with early-onset CHD were significantly less likely to have annual incomes of $\$ 35,000$ or more. As expected, reports of personal history of stroke, diabetes, hypertension, hypercholesterolemia, and obesity were significantly greater among respondents with early-onset CHD compared with respondents without $\mathrm{CHD}$.

\section{Prevalence of familial disease}

Among all respondents, approximately half reported having at least one first- or second-degree relative with $\mathrm{CHD}$, and approximately three quarters (76.6\%) had a family history of $\mathrm{CHD}$, stroke, or diabetes. Family history of stroke was reported more often by women $(46.9 \%)$ than men $(39.0 \%)(P<.0001)$.
Frequency of family history of diabetes was similar for women (43.1\%) and men (41.2\%). The most prevalent family history reported by respondents included CHD, stroke, and diabetes in first- and/or second-degree relatives (15.8\%), followed by CHD and stroke (14.6\%), CHD only (11.8\%), diabetes only (11.1\%), CHD and diabetes (9.8\%), stroke only (7.7\%), and stroke and diabetes $(5.6 \%)$.

\section{Awareness of family history}

In general, for both CHD and stroke, the respondents had significantly fewer "don't know" responses for disease status among first-degree relatives compared with second-degree relatives (data not shown). Respondents also had significantly greater awareness about disease status in mothers versus fathers and maternal compared with paternal second-degree relatives. Women and men had similar awareness of CHD, stroke, and diabetes among firstand second-degree relatives; however, women had fewer "don't know" responses (16.9\%) than men (19.5\%) concerning stroke in first-degree relatives $(P=.03)$.

\section{Family history of coronary heart disease}

Prevalence ORs for individual characteristics of family history of CHD (e.g., age at onset, number of relatives affected, type or lineage of affected relatives) associated with personal history of early-onset CHD adjusted for demographic factors and self-reports of hypercholesterolemia, hypertension, and obesity are presented in Table 2. Combinations of these family history characteristics were not assessed. No significant sexspecific differences were found. In all analyses, the referent group was composed of respondents with no family history of CHD in first- or second-degree relatives.

In regard to age of onset, having at least one first-degree relative with early-onset $\mathrm{CHD}(\mathrm{OR}=5.0,95 \%$ confidence interval $[\mathrm{CI}] 2.8-8.7)$ or at least one first-degree relative with late-onset $\mathrm{CHD}(\mathrm{OR}=2.5,95 \% \mathrm{CI} 1.2-5.3)$ was significantly associated with personal history of early-onset CHD. Regardless of the age of onset, having only one first-degree relative $(\mathrm{OR}=3.0,95 \%$ CI 1.7-5.4) or two or more first-degree relatives with $\mathrm{CHD}(\mathrm{OR}=5.1,95 \%$ CI 2.8-9.4) was significantly associated with personal history of early-onset CHD. In regard to the type and lineage of first-degree relatives with $\mathrm{CHD}$, the strength of association with early-onset CHD was similar (increased approximately threefold) given a mother, father, or sibling with $\mathrm{CHD}$, and the strength of the association increased if a parent and a sibling had CHD $(\mathrm{OR}=5.0,95 \% \mathrm{CI} 2.2-11.1)$ or if both parents were affected ( $\mathrm{OR}=6.2,95 \% \mathrm{CI} 2.9-13.3$ ).

In regard to age of onset, regardless of number or lineage of affected second-degree relatives, having at least one seconddegree relative (and no first-degree relative) with early-onset $\mathrm{CHD}$ was significantly associated with early-onset $\mathrm{CHD}(\mathrm{OR}=$ $4.6,95 \%$ CI 2.1-10.3). There were too few observations to assess the association between second-degree relatives with lateonset CHD and personal history of early-onset CHD. Having two or more second-degree relatives with $\mathrm{CHD}$, regardless of the age of onset or lineage, was significantly associated with early-onset $\mathrm{CHD}(\mathrm{OR}=2.8,95 \% \mathrm{CI} 1.3-6.0)$. 
Table 2

Associations between various definitions of family history of coronary heart disease and early-onset coronary heart disease

\begin{tabular}{lccc}
\hline & Early-onset CHD & No CHD & Prevalence OR $^{a}$ for early-onset CHD \\
Definitions of family history of CHD & $\mathrm{N}=178$ & $\mathrm{~N}=3778$ & $(95 \% \mathrm{CI})$ \\
\hline
\end{tabular}

\section{First-degree relatives only}

Having at least 1 first-degree relative with CHD (and no affected second-degree relative) regardless of age at onset, number, type, or lineage

No family history ${ }^{b}$

Age of onset

Regardless of number, type, or lineage of first-degree relatives with $\mathrm{CHD}$, having at least 1 relative with:

Early-onset CHD

Late-onset CHD

Early- and late-onset CHD

No family history ${ }^{b}$

Number of affected relatives

Regardless of age of onset, type, or lineage of first-degree relatives with $\mathrm{CHD}$, having:

1 relative with CHD

$>2$ relatives with $\mathrm{CHD}$

No family history ${ }^{b}$

Type of affected relatives

Regardless of age of onset or number of first-degree relatives with CHD, having a:

Sibling with CHD

Parent with CHD

Parent and sibling with CHD

No family history ${ }^{b}$

Lineage of affected relatives

Regardless of age of onset or number of first-degree relatives with $\mathrm{CHD}$, having a:

Nuclear relative with $\mathrm{CHD}^{c}$

Maternal relative with $\mathrm{CHD}^{d}$

Paternal relative with $\mathrm{CHD}^{e}$

Maternal and paternal relative with $\mathrm{CHD}^{d, e}$

No family history ${ }^{b}$

\section{Second-degree relatives only}

Having at least 1 second-degree relative with CHD (and no affected first-degree relative) regardless of age at onset, number, or lineage

No family history ${ }^{b}$

Age of onset Regardless of number or lineage of second-degree relatives
with CHD, having at least 1 relative with:

Early-onset CHD

Early- and late-onset CHD 
Table 2

Continued

\begin{tabular}{|c|c|c|c|}
\hline Definitions of family history of CHD & $\begin{array}{l}\text { Early-onset CHD } \\
\mathrm{N}=178\end{array}$ & $\begin{array}{l}\text { No CHD } \\
\mathrm{N}=3778\end{array}$ & $\begin{array}{l}\text { Prevalence } \mathrm{OR}^{a} \text { for early-onset CHD } \\
\qquad(95 \% \mathrm{CI})\end{array}$ \\
\hline \multicolumn{4}{|l|}{ Number of affected relatives } \\
\hline \multicolumn{4}{|l|}{$\begin{array}{l}\text { Regardless of age of onset or lineage of second-degree } \\
\text { relatives with CHD, having: }\end{array}$} \\
\hline 1 relative with $\mathrm{CHD}$ & 5 & 290 & $1.3(0.5-3.7)$ \\
\hline$>2$ relatives with $\mathrm{CHD}$ & 15 & 377 & $2.8(1.3-6.0)$ \\
\hline No family history ${ }^{b}$ & 33 & 1701 & 1.0 \\
\hline \multicolumn{4}{|l|}{ Lineage of affected relatives } \\
\hline \multicolumn{4}{|l|}{$\begin{array}{l}\text { Regardless of age of onset or number of second-degree } \\
\text { relatives with CHD, having a: }\end{array}$} \\
\hline Maternal relative with $\mathrm{CHD}$ & 5 & 271 & $1.2(0.4-3.6)$ \\
\hline Paternal relative with CHD & 6 & 205 & $2.3(0.9-6.2)$ \\
\hline Maternal and paternal relative with $\mathrm{CHD}$ & 9 & 191 & $3.3(1.3-8.0)$ \\
\hline No family history ${ }^{b}$ & 33 & 1701 & 1.0 \\
\hline \multicolumn{4}{|l|}{ First- and second-degree relatives } \\
\hline $\begin{array}{l}\text { Having at least } 1 \text { first-degree and } 1 \text { second-degree relative } \\
\text { with CHD regardless of age at onset, number, or lineage }\end{array}$ & 72 & 666 & $4.5(2.8-7.3)$ \\
\hline No family history ${ }^{b}$ & 33 & 1701 & 1.0 \\
\hline \multicolumn{4}{|l|}{ Age of onset } \\
\hline \multicolumn{4}{|l|}{$\begin{array}{l}\text { Regardless of number or lineage of first- and second-degree } \\
\text { relatives with CHD, having at least } 1 \text { first-degree and } 1 \\
\text { second-degree relative with: }\end{array}$} \\
\hline Early-onset CHD & 21 & 117 & $9.8(4.9-19.5)$ \\
\hline Late-onset CHD & 4 & 89 & NA \\
\hline Early- and late-onset CHD & 47 & 460 & $4.1(2.4-6.9)$ \\
\hline No family history ${ }^{b}$ & 33 & 1701 & 1.0 \\
\hline \multicolumn{4}{|l|}{ Number of affected relatives } \\
\hline \multicolumn{4}{|l|}{$\begin{array}{l}\text { Regardless of age of onset or lineage of first- and second- } \\
\text { degree relatives with CHD, having: }\end{array}$} \\
\hline 1 first- and 1 second-degree relative with CHD & 8 & 116 & $3.0(1.3-7.4)$ \\
\hline$>3$ first- and second-degree relatives with CHD & 64 & 550 & $4.7(2.9-7.7)$ \\
\hline No family history ${ }^{b}$ & 33 & 1701 & 1.0 \\
\hline \multicolumn{4}{|l|}{ Lineage of affected relatives } \\
\hline \multicolumn{4}{|l|}{$\begin{array}{l}\text { Regardless of age of onset or number of first- and second- } \\
\text { degree relatives with CHD, having: }\end{array}$} \\
\hline Maternal relatives with CHD & 14 & 117 & $5.5(2.7-11.4)$ \\
\hline Paternal relatives with CHD & 8 & 124 & $2.9(1.2-7.1)$ \\
\hline Maternal and paternal relatives with $\mathrm{CHD}$ & 50 & 425 & $4.5(2.7-7.6)$ \\
\hline No family history ${ }^{b}$ & 33 & 1701 & 1.0 \\
\hline
\end{tabular}

CHD, coronary heart disease; early-onset CHD, disease at or before age 60 years; OR, odds ratio; CI, confidence interval; NA, not available (because there were too few observations to calculate).

${ }^{a}$ Adjusted for age, race/ethnicity, marital status, education, income, self-reported obesity, hypercholesterolemia, and hypertension.

${ }^{b}$ No first- or second-degree relatives with CHD.

'Sibling(s) only.

${ }^{d}$ Mother only or mother and sibling $(\mathrm{s})$.

${ }^{e}$ Father only or father and sibling(s). 
Table 3

Associations between various definitions of family history of stroke and early-onset coronary heart disease

\begin{tabular}{lccc}
\hline & Early-onset CHD & No CHD & Prevalence OR $^{a}$ for early-onset CHD \\
Definitions of family history of stroke & $(\mathrm{N}=178)$ & $(\mathrm{N}=3778)$ & $(95 \% \mathrm{CI})$ \\
\hline
\end{tabular}

\section{First-degree only}

Having at least 1 first-degree relative with stroke (and no number, type, or lineage

No family history ${ }^{b}$

Age of onset

Regardless of number, type, or lineage of first-degree relatives with stroke, having at least 1 relative with:

Early-onset stroke

Late-onset stroke

Early- and late-onset stroke

No family history ${ }^{b}$

Number of affected relatives

Regardless of age of onset, type, or lineage of first-degree relatives with stroke, having:

1 relative with stroke

$>2$ relatives with stroke

No family history ${ }^{b}$

Type of affected relatives

Regardless of age of onset or number of first-degree relatives with stroke, having a:

Sibling with stroke

Parent with stroke

Parent and sibling with stroke

No family history ${ }^{b}$

Lineage of affected relatives

Regardless of age of onset or number of first-degree relatives with stroke, having a:

Nuclear relative with stroke ${ }^{d}$

Maternal relative with stroke $e^{e}$

Paternal relative with stroke $e^{f}$

Maternal and paternal relatives with stroke $e^{e, f}$

No family history ${ }^{b}$

\section{Second-degree only}

Having at least 1 second-degree relative with stroke (and no affected first-degree relative) regardless of age at onset, number, or lineage

No family history ${ }^{b}$

Age of onset
Regardless of number or lineage of second-degree relatives with stroke, having at least 1 relative with:

\section{Early-onset stroke}

Early- and late-onset stroke

$1.5(0.6-4.0)$

1.0

(continued on next page) 
Table 3

Continued

\begin{tabular}{|c|c|c|c|}
\hline Definitions of family history of stroke & $\begin{array}{l}\text { Early-onset CHD } \\
\quad(\mathrm{N}=178)\end{array}$ & $\begin{array}{l}\text { No CHD } \\
(\mathrm{N}=3778)\end{array}$ & $\begin{array}{l}\text { Prevalence } \mathrm{OR}^{a} \text { for early-onset CHD } \\
\qquad(95 \% \mathrm{CI})\end{array}$ \\
\hline \multicolumn{4}{|l|}{ Number of affected relatives } \\
\hline \multicolumn{4}{|l|}{$\begin{array}{l}\text { Regardless of age of onset or lineage of second-degree relatives } \\
\text { with stroke, having: }\end{array}$} \\
\hline 1 relative with stroke & 9 & 332 & $1.2(0.5-2.6)$ \\
\hline$>2$ relatives with stroke & 13 & 235 & $0.3(0.1-0.9)$ \\
\hline No family history $^{b}$ & 81 & 2139 & 1.0 \\
\hline \multicolumn{4}{|l|}{ Lineage of affected relatives } \\
\hline \multicolumn{4}{|l|}{$\begin{array}{l}\text { Regardless of age of onset or number of second-degree } \\
\text { relatives with stroke, having a: }\end{array}$} \\
\hline Maternal relative with stroke & 10 & 262 & $1.4(0.7-3.0)$ \\
\hline Paternal relative with stroke & 6 & 178 & $1.7(0.7-4.4)$ \\
\hline Maternal and paternal relative with stroke & 6 & 127 & $1.4(0.5-3.9)$ \\
\hline No family history ${ }^{b}$ & 81 & 2139 & 1.0 \\
\hline \multicolumn{4}{|l|}{ First and second-degree relatives } \\
\hline $\begin{array}{l}\text { Having at least } 1 \text { first-degree and } 1 \text { second-degree relative with } \\
\text { stroke regardless of age of onset, number, or lineage } e^{c}\end{array}$ & $\begin{array}{l}\mathrm{F}: 19 \\
\mathrm{M}: 5\end{array}$ & $\begin{array}{l}\mathrm{F}: 246 \\
\mathrm{M}: 125\end{array}$ & $\begin{array}{r}\text { F:2.4 (1.3-4.4) } \\
\text { M:0.7 (0.2-1.8) }\end{array}$ \\
\hline No family history ${ }^{b}$ & 81 & 2139 & 1.0 \\
\hline \multicolumn{4}{|l|}{ Age of onset } \\
\hline \multicolumn{4}{|l|}{$\begin{array}{l}\text { Regardless of number or lineage of first- and second-degree } \\
\text { relatives with stroke, having at least } 1 \text { first-degree and } 1 \\
\text { second-degree relative with: }\end{array}$} \\
\hline Early-onset stroke & 0 & 34 & NA \\
\hline Late-onset stroke & 5 & 114 & $1.1(0.4-3.0)$ \\
\hline \multirow[t]{2}{*}{ Early- and late-onsetstroke ${ }^{c}$} & $\mathrm{~F}: 15$ & F:105 & F:3.1 (1.6-6.1) \\
\hline & M:4 & M:73 & NA \\
\hline No family history ${ }^{b}$ & 81 & 2139 & 1.0 \\
\hline \multicolumn{4}{|l|}{ Number of affected relatives } \\
\hline \multicolumn{4}{|l|}{$\begin{array}{l}\text { Regardless of age of onset or lineage of first- and second- } \\
\text { degree relatives with stroke, having: }\end{array}$} \\
\hline 1 first- and 1 second-degree relative with stroke & 6 & 130 & $1.2(0.5-2.9)$ \\
\hline \multirow[t]{2}{*}{$>3$ first- and second-degree relatives with stroke ${ }^{c}$} & $\mathrm{~F}: 13$ & $\mathrm{~F}: 158$ & $\mathrm{~F}: 2.5(1.2-5.2)$ \\
\hline & M:5 & M:83 & M:0.9 (0.3-2.4) \\
\hline No family history ${ }^{b}$ & 81 & 2139 & 1.0 \\
\hline \multicolumn{4}{|l|}{ Lineage of affected relative } \\
\hline \multicolumn{4}{|l|}{$\begin{array}{l}\text { Regardless of age of onset or number of first- and second- } \\
\text { degree relatives with stroke, having: }\end{array}$} \\
\hline Maternal relatives with stroke & 2 & 108 & NA \\
\hline Paternal relatives with stroke & 8 & 65 & $2.7(1.1-6.3)$ \\
\hline Maternal and paternal relatives with stroke & 2 & 108 & NA \\
\hline No family history ${ }^{b}$ & 81 & 2139 & 1.0 \\
\hline
\end{tabular}

CHD, coronary heart disease; early-onset CHD, disease at or before age 60 years; F, female; $\mathrm{M}$, male; NA, not available (because there were too few observations to calculate).

${ }^{a}$ Adjusted for age, race/ethnicity, marital status, education, income, self-reported obesity, hypercholesterolemia, and hypertension.

${ }^{b}$ No first- or second-degree relatives with stroke.

${ }^{c}$ Significant interaction between sex and family history $(P<.05)$ was found, and interaction term was included in the regression model.

${ }^{d}$ Sibling(s) only.

${ }^{e}$ Mother only or mother and sibling(s).

${ }^{f}$ Father only or father and sibling(s). 


\section{Scheuner et al.}

The most significant association with early-onset CHD was found when both first- and second-degree relatives had earlyonset CHD (OR $=9.8,95 \% \mathrm{CI} 4.9-19.5)$. The strength of association increased with increasing numbers of affected firstand second-degree relatives, and given affected maternal relatives compared with paternal relatives, although the differences were not statistically significant.

\section{Family history of stroke}

The associations between various family history definitions of stroke and personal history of early-onset CHD adjusted for demographic factors and self-reports of hypercholesterolemia, hypertension, and obesity are presented in Table 3. Combinations of these family history characteristics were not assessed. In all analyses, the referent group was composed of respondents with no family history of stroke in first- or second-degree relatives.

History of early-onset stroke in at least one first-degree relative was significantly associated with personal history of early-onset $\mathrm{CHD}(\mathrm{OR}=2.9,95 \%$ CI 1.7-5.0). Having two or more firstdegree relatives with stroke, regardless of age of onset, was not associated with early-onset CHD in women, and there were too few observations of men with this family history to assess the association with early-onset CHD. When only first-degree relatives were affected with stroke, sibling history was significantly associated with personal history of early-onset $\mathrm{CHD}(\mathrm{OR}=3.2,95 \% \mathrm{CI}$ 1.2-8.3). However, stroke in one or both parents was not. The number of parent and sibling pairs with stroke was too small to assess associations with early-onset CHD.

No significant associations with early-onset CHD were observed given only second-degree relatives with stroke. When both first and second-degree relatives were affected, there was a significant association with early-onset $\mathrm{CHD}$ if these relatives were on the paternal side of the family ( $\mathrm{OR}=2.7,95 \% \mathrm{CI}$ 1.1-6.3). There were too few maternal first- and second-degree relatives with stoke to assess an association with earlyonset CHD. Among female respondents, significant associations with early-onset CHD were observed given affected first- and second-degree relatives at any age of onset regardless of the lineage of affected relatives $(\mathrm{OR}=2.4,95 \% \mathrm{CI}$ 1.3-4.4). There were too few male respondents with affected first- and second-degree relatives to assess an association with early-onset CHD.

\section{Family history of diabetes}

A family history of at least one first-degree relative with diabetes was reported by $67.9 \%(55 / 81)$ of women and $51.5 \%$ (50/97) of men with early-onset CHD, compared with $42.2 \%$ (973/2307) of women and 40.6\% (597/1471) of men without CHD. This family history was significantly associated with early-onset $\mathrm{CHD}$ in women $(\mathrm{OR}=2.4,95 \% \mathrm{CI} 1.5-4.0)$, but not in men $(\mathrm{OR}=1.1,95 \%$ CI $0.7-1.7)$.

\section{DISCUSSION}

In this cross-sectional survey, we found that family histories of $\mathrm{CHD}$, stroke, and diabetes were prevalent and significantly asso-
Table 4

Summary of significant associations between family history and early-onset coronary heart disease

Family history definitions

$\geq 1$ first-degree relative with early-onset CHD

$\geq 1$ first-degree relative with late-onset CHD

1 first-degree relative with $\mathrm{CHD}$ at any age of onset

$\geq 2$ first-degree relatives with CHD at any age of onset

$\geq 1$ sibling with CHD at any age of onset

$\geq 1$ parent with CHD at any age of onset

Parent and sibling pair with CHD at any age of onset

Maternal first-degree relatives ${ }^{a}$ with $\mathrm{CHD}$ at any age of onset

Paternal first-degree relatives ${ }^{b}$ with CHD at any age of onset

Maternal and paternal first-degree relatives ${ }^{a, b}$ with CHD at any age of onset

$\geq 1$ second-degree relative with early-onset CHD

$\geq 2$ second-degree relatives with CHD at any age of onset

First- and second-degree relatives with CHD at any age of onset

$\geq 1$ first-degree relative with early-onset stroke

$\geq 1$ sibling with stroke at any age of onset

First- and second-degree relatives with stroke at any age of onset ${ }^{c}$

$\geq 1$ first-degree relative with diabetes ${ }^{c}$

CHD, coronary heart disease; early-onset CHD, disease at or before age 60 years; late-onset $\mathrm{CHD}$, disease after age 60 years.

${ }^{a}$ Mother only or mother and siblings.

${ }^{b}$ Father only or father and siblings.

${ }^{c}$ Significant association among women only.

ciated with self-reported, early-onset CHD. We investigated various definitions of family history beyond early-onset $\mathrm{CHD}$ in firstdegree relatives and identified several significant associations with CHD diagnosed at or before age 60 years (Table 4).

\section{Early-onset versus late-onset coronary heart disease in relatives}

Several studies have shown CHD risk is greater given younger ages of onset in relatives. ${ }^{3,7-10,14,25,26}$ Studies that have investigated family history of late-onset disease have found positive associations with $\mathrm{CHD}$, although comparatively the relative risks are smaller. ${ }^{7-10,25,26}$ We found significant increases in early-onset CHD given early-onset CHD in either first- or second-degree relatives. Late-onset CHD in first-degree relatives was also significantly associated with early-onset $\mathrm{CHD}$; however, the strength of association was reduced by half, 5.0 -fold versus 2.5 -fold increase, respectively. There were too few observations to assess associations between early-onset $\mathrm{CHD}$ given second-degree relatives with late-onset CHD.

\section{Second-degree relatives with coronary heart disease}

A recent study described a significant association between family history of premature CHD in second-degree relatives and coronary artery calcification in men aged 40 to 50 years. ${ }^{27}$ We found that CHD in second-degree relatives, even in the absence of CHD in a first-degree relative, is significantly asso- 
ciated with self-reports of early-onset CHD, and this seems to be attributable in large part to early-onset disease or having more than one affected second-degree relative. In addition, having second-degree relatives with early-onset CHD substantially increased the strength of association with CHD compared with having affected first-degree relatives only. To our knowledge, this is the first report of these key findings. These results have important implications for CHD risk assessment. Traditionally, assessment of family history has been limited to first-degree relatives. This limitation may be attributable in large part to a lack of data collection regarding second-degree relatives in large epidemiologic or clinical investigations of $\mathrm{CHD}$, and as a result evidence about the impact of this information on CHD risk has been lacking.

\section{Number of relatives with coronary heart disease}

Several studies have shown increasing magnitude in CHD risk with increasing numbers of first-degree relatives with CHD. $7,8,14,15,26,28$ Our results confirm this association, and we identified the same trend given increasing numbers of seconddegree relatives with CHD regardless of age at onset or lineage.

\section{Lineage of relatives with coronary heart disease}

We found that when only first-degree relatives are affected, having an affected mother or father conferred a similar risk for early-onset CHD. However, when both first- and second-degree relatives are affected with $\mathrm{CHD}$, there seemed to be a stronger association given affected maternal relatives compared with paternal relatives; however, the differences are not significant. Results from the Physicians' Health Study and the Women's Health Study found maternal history of MI was more strongly associated with MI at any age than was a paternal history of MI. ${ }^{25}$ Other studies $^{6,14,28,29}$ have not identified an effect of lineage on CHD risk, perhaps because their definition of positive family history of $\mathrm{CHD}$ was restricted to first-degree relatives and, as in our analyses, considered only the outcome of early-onset CHD.

\section{Type of relative with coronary heart disease}

We did not find a substantial difference in risk for early-onset $\mathrm{CHD}$ given parental or sibling history of CHD. Our findings differ from those of other reports. A case-control study of women aged 18 to 44 years found sibling history of CHD was a stronger risk factor than parental history. ${ }^{30}$ Silberberg et al. ${ }^{8}$ also found greater risk with sibling history, and more recently, sibling history of $\mathrm{CHD}$ was described as a stronger risk factor for subclinical CHD. ${ }^{31}$ The discrepancy in the results of these studies and ours may be explained by demographic differences, such as a younger age of study participants or different clinical end points in other studies (i.e., self-reports of CHD vs. subclinical CHD).

$\mathrm{CHD}$ is a complex disease because of interactions of genetic and environmental risk factors, and family history is currently the best method available to assess the interaction of these shared risk factors. ${ }^{32}$ Given that shared environmental effects on CHD risk are stronger for sibling pairs than parent-offspring pairs, ${ }^{33,34}$ results from previous studies seem to suggest a more important role for environmental/behavioral factors contributing to familial aggregation of CHD. However, the results of our study are not consistent with this notion; we found similar ORs for early-onset CHD given affected siblings or affected parents, and a stronger association if parents and siblings were both affected. These results suggest genetic factors that travel across generations play an important role in susceptibility to early-onset CHD. This idea is further supported by our finding of significant associations with CHD given first and second-degree relatives with $\mathrm{CHD}$ from one lineage (maternal or paternal).

\section{Family history of stroke}

Our results show that family history of early-onset stroke in first-degree relatives was significantly associated with earlyonset CHD in all respondents. Unlike the situation with CHD, we did find that sibling history of stroke, but not parental history, was significantly associated with early-onset CHD. This finding suggests an important role for environmental or behavioral factors in explaining this association, or a recessive mechanism for a major gene or genes involved in CHD susceptibility might be responsible for the observation. However, a recessive gene or genes seem less likely given our observation that, at least among women, early-onset CHD was significantly more likely given an increasing number of relatives with stroke across generations (first- and second-degree relatives). The number of males with this type of family history was too small to assess an association. The Rancho Bernardo study found family history of stroke in any first-degree relative was an independent predictor of ischemic heart disease mortality in men, but not in women. ${ }^{35}$ Because that study's family history data did not include age of stroke onset or second-degree relatives, the investigators may have been limited in detecting the significant associations that we found in women. Other reports investigating the effect of stroke family history on CHD risk have found positive associations, but none have assessed the association according to sex. ${ }^{36-38}$

\section{Family history of diabetes}

We found that family history of diabetes was significantly associated with early-onset CHD in women, but not in men. To our knowledge, this is the first report of this association. A previous study showed that family history of diabetes was associated with CHD in persons with type 1 diabetes. ${ }^{39}$ Although family history of diabetes was not associated with CHD mortality in the Rancho Bernardo study, those participants with a family history of diabetes included a greater proportion with a family history of heart attack. ${ }^{24}$

Diabetes is a stronger risk factor for CHD in women than in men. ${ }^{40,41}$ Our results suggest that genetic or environmental/ behavioral factors shared by family members contribute to the $\mathrm{CHD}$ associated with diabetes in women, rather than factors solely associated with the internal milieu of females (e.g., hormones). Additional evidence for diabetes-related genetic factors contributing to $\mathrm{CHD}$ among women comes from a study that found the influence of genetic factors on body fat, insulin, 
and cardiovascular disease differed between the sexes, with higher heritability estimates for women. ${ }^{42}$

\section{Study strengths and limitations}

The major strengths of this study are the large number of respondents to the HealthStyles survey and the equal representation of the sexes across a range of adult age groups. However, because of the limited number of respondents with late-onset CHD ( $\mathrm{n}=79$ ) we were unable to assess associations between the various family history definitions investigated in this study and personal history of late-onset CHD. In addition, although the survey is population-based, it is subject to selection bias because the participants are voluntary respondents and thus not randomly drawn from the U.S. population. In addition, the cross-sectional design prohibits establishment of any temporal associations concerning family history as a risk factor, and because the data were obtained from prevalent cases the results may be confounded by survival.

Another potential limitation is lack of validation of self-reports. A previous study showed that self-reports of CHD and risk factors are reliable, ${ }^{43}$ and several studies have investigated the validity of family history reports. For family history of CHD in first-degree relatives, sensitivity ranges from $67 \%$ to $89 \%$, and specificity ranges from $59 \%$ to $97 \%$, with most values greater than $90 \% .^{8,30,44-47}$ Sensitivity values range from $56 \%$ to $87 \%$ for family history of diabetes, and specificity ranges from $97 \%$ to $98 \% .{ }^{44,47}$ For family history of stroke, sensitivity ranges from $42 \%$ to $51 \%$ with a specificity from $96 \%$ to $98 \% .{ }^{47} \mathrm{~A}$ personal history of CHD or having a CHD risk factor such as hypertension, diabetes, or hypercholesterolemia generally does not affect the accuracy of the family history report, nor does gender. ${ }^{44,45,47}$ However, older individuals are more likely to give inaccurate family history compared with younger individuals. ${ }^{44,47}$ Limited information is available regarding the influence of ethnicity/race on accuracy of family history reports. However, in the National Heart, Lung, and Blood Institute Family Heart Study, there were no significant differences in family history accuracy between whites and African Americans reporting on $\mathrm{CHD}$, diabetes, and hypertension. ${ }^{44}$ Similar results were found in a study investigating the validity of cancer family history data; race or ethnicity did not influence the accuracy of reporting. ${ }^{48}$ There are no available reports regarding the validity of family history of CHD, stroke, or diabetes in second-degree relatives; however, review of the cancer literature has shown decreased accuracy of reports with increasing degree of relationship, yet specificity tends to remain high. ${ }^{48,49}$ Given these estimates of validity, a family history of CHD, stroke, or diabetes generally can be considered as accurate, with little overreporting of disease in close family members.

We found some sex-specific differences regarding certain types of family history associated with CHD. These differences might be attributable in part to differences in unmeasured demographic or cardiovascular risk factors, such as smoking and inactivity, that could affect the associations between family history and CHD. Alternatively, the sex-specific differences in family history reporting might reflect a reporting bias. How- ever, such bias has not been observed in studies investigating accuracy of family history reporting. ${ }^{8,44,47}$

We also found differences in awareness of disease according to lineage. Respondents knew more about the presence or absence of disease (there were fewer "don't know" responses) for maternal relatives compared with paternal relatives. Other investigators studying family history reports of breast cancer have also found more reports of breast cancer among maternal relatives compared with paternal relatives, even after excluding cases with affected mothers. ${ }^{50,51}$ However, the cause for these differences is not known and is deserving of further study. It may be that such differences reflect true biologic differences attributable to mitochondrial inheritance, epigenetic factors, or in utero effects, or it may be true reporting bias because of lack of information about paternal relatives or reduced family communication about disease in paternal relatives.

The impact of lifestyle risk factors could not be assessed in this study, such as smoking, inactivity, and diet, because these data were not collected in the HealthStyles 2003 survey. These risk factors are often shared by family members and could underlie some of the patterns of familial risk we observed in this study. However, we could not discern the contribution of these factors in our analyses, which also limited our ability to infer the possible benefit resulting from preventive interventions targeted to these risk factors. Tavani et al. ${ }^{52}$ showed that individuals with increased familial risk for CHD may derive the greatest benefit from traditional preventive strategies.

\section{SUMMARY AND IMPLICATIONS}

Family histories of $\mathrm{CHD}$, stroke, or diabetes are prevalent. We found significant associations between personal history of early-onset CHD and additional family history that goes beyond having first-degree relatives with early-onset CHD. For the first time we describe significant associations between personal history of early-onset $\mathrm{CHD}$ and having second-degree relatives with $\mathrm{CHD}$, and we describe a significant association between family history of diabetes and personal history of early-onset CHD in women, but not in men. We also showed that the type or lineage of affected relatives can influence earlyonset CHD, and that sex can affect associations between certain definitions of family history and CHD. We also confirmed an association between family history of stroke and early-onset CHD. Confirmation of our findings in large, population-based studies is needed. If replicated, these results may have important implications for risk assessment and prevention of CHD.

\section{ACKNOWLEDGMENTS}

This work was supported by a Career Development Award sponsored by the Association of Teachers of Preventive Medicine in collaboration with the Centers for Disease Control and Prevention, Cooperative Agreement U50/CCU300860 (M.T.S.). We thank Roger S. Blumenthal, MD, for his helpful comments on an earlier version of this article.

\section{References}

1. American Heart Association. Heart Disease and Stroke Statistics-2005 Update. Dallas, TX: American Heart Association; 2005. 
2. Smith SC, Greenland P, Grundy SM. AHA Conference Proceedings. Prevention Conference V. Beyond secondary prevention: identifying the high-risk patient for primary prevention. Executive summary. Circulation 2000;101:111-116.

3. Slack J, Evans KA. The increased risk of death from ischaemic heart disease in first-degree relatives of 121 men and 96 women with ischaemic heart disease. J Med Genet 1966;3:239-257.

4. Friedlander Y, Kark JD, Stein Y. Family history of myocardial infarction as an independent risk factor for coronary heart disease. Br Heart J 1985;53:382-387.

5. Thomas $\mathrm{CB}$, Cohen $\mathrm{BH}$. The familial occurrence of hypertension and coronary artery disease, with observations concerning obesity and diabetes. Ann Intern Med 1955;42:90-127.

6. Lloyd-Jones DM, Nam B-H, D'Agostino Levy D, et al. Parental cardiovascular disease as a risk factor for cardiovascular disease in middle-aged adults. A prospective study of parents and offspring. JAMA 2004;291:2204-2211.

7. Hunt SC, Williams RR, Barlow GK. A comparison of positive family history definitions for defining risk of future disease. J Chronic Dis 1986;39:809-821.

8. Silberberg JS, Wlodarczyk J, Fryer J, Ray CD, et al. Correction for biases in a population-based study of family history and coronary heart disease. The Newcastle Family History Study I. Am J Epidemiol 1998;147:1123-1132.

9. Brown DW, Giles WH, Burke W, Greenlund KJ, et al. Familial aggregation of earlyonset myocardial infarction. Community Genet 2002;5:232-238.

10. Nora JJ, Lortscher RH, Spangler RD, Nora AH, et al. Genetic-epidemiologic study of early-onset ischemic heart disease. Circulation 1980;61:503-508.

11. Wilson PWF, D'Agostino RB, Levy D, Belanger AM, et al. Prediction of coronary heart disease using risk factor categories. Circulation 1998;97:1837-1847.

12. National Cholesterol Education Program (NCEP) Expert Panel on Detection, Evaluation, and Treatment of High Blood Cholesterol in Adults (Adult Treatment Panel III). Third Report of the National Cholesterol Education Program (NCEP) Expert Panel on Detection, Evaluation, and Treatment of High Blood Cholesterol in Adults (Adult Treatment Panel III) final report. Circulation 2002;106:3143-3421.

13. Pollard WE. Use of consumer panel survey data for public health communication planning; an evaluation of survey results. In: Proceedings of the Section on Health Policy Statistics. Alexandria, VA: American Statistical Association; 2002:2720-2724.

14. Ciruzzi M, Schargrodsky H, Rozlosnik J, Pramparo P, et al. Frequency of family history of acute myocardial infarction in patients with acute myocardial infarction. Am J Cardiol 1997;80:122-127.

15. Leander K, Hallqvist J, Reuterwall C, Ahlbom A, et al. Family history of coronary heart disease, a strong risk factor for myocardial infarction interacting with other cardiovascular risk factors: results for the Stockholm Heart Epidemiology Program (SHEEP). Epidemiology 2001;12:215-221.

16. Bensen JT, Li R, Hutchinson RG, Province MA, et al. Family history of coronary heart disease and pre-clinical carotid artery atherosclerosis in African Americans and Whites: the ARIC Study. Genet Epidemiol 1999;16:165-178.

17. Colditz GA, Stampfer MJ, Willett WC, Rosner B, et al. A prospective study of parental history of myocardial infarction and coronary heart disease in women. Am J Epidemiol 1986;123:48-58.

18. Phillips RL, Lilienfeld AM, Diamond EL, Kagan A. Frequency of coronary heart disease and cerebrovascular accidents in parents and sons of coronary heart disease index cases and controls. Am J Epidemiol 1974;100:87-100.

19. Rissanen AM, Nikkila EA. Coronary artery disease and its risk factors in families of young men with angina pectoris and in controls. Br Heart J 1977;39:875-883.

20. Spriggs DA, French JM, Murdy JM, Bates D, et al. Historical risk factors for stroke: a case control study. Age Ageing 1990;19:280-287.

21. Brass LM, Shaker LA. Family history in patients with transient ischemic attacks. Stroke 1991;22:837-841.

22. Kiely DK, Wolf PA, Cupples LA, Beiser AS, et al. Familial aggregation of stroke. The Framingham Study. Stroke 1993;24:1366-1371.

23. Graffagnino C, Gasecki AP, Doig GS, Hachinski VC. The importance of family history in cerebrovascular disease. Stroke 1994;25:1599-1604.

24. Wingard DL, Barrett-Connor E. Family history of diabetes and cardiovascular disease risk factors and mortality among euglycemic, borderline hyperglycemic, and diabetic adults. Am J Epidemiol 1987;125:948-958.

25. Sesso HD, Lee I-M, Gaziano M, Rexrode KM, et al. Maternal and paternal history of myocardial infarction and risk of cardiovascular disease in men and women. Circulation 2001;104:393-398.

26. Roncaglioni MC, Santoro L, D'Avanzo B, Negri E, et al. Role of family history in patients with myocardial infarction. An Italian case-control study. GISSI-EFRIM Investigators. Circulation 1992;85:2065-2072.

27. Taylor AJ, Bindeman J, Bhattarai S, Feuerstein IM, et al. Subclinical calcified atherosclerosis in men and its association with a family history of premature coronary heart disease in first- and second-degree relatives. Prev Cardiol 2004;7:163-167.
28. Bertuzzi M, Negri E, Tavani A, LaVecchia C. Family history of ischemic heart disease and risk of acute myocardial infarction. Prev Med 2003;37:183-187.

29. Kinra S, Davey Smith G, Okasha M, McCarron P, et al. Is maternal transmission of coronary heart disease risk stronger than paternal transmission? Heart 2003;89:834838 .

30. Friedlander Y, Arbogast P, Schwartz SM, Marcovina SM, et al. Family history as a risk factor for early onset myocardial infarction in young women. Atherosclerosis 2001;156:201-207.

31. Nasir K, Michos ED, Rumberger JA, Braunstein JB, et al. Coronary artery calcification and family history of premature coronary heart disease: sibling history is more strongly associated than parental history. Circulation 2004;110:2150-2156.

32. Scheuner MT, Wang S-J, Raffel LJ, Larabell SK, et al. Family history: a comprehen sive genetic risk assessment method for the chronic conditions of adulthood. Am J Med Genet 1997;71:315-324.

33. Harrap SB, Stebbing M, Hopper JL, Hoang HN, et al. Familial patterns of covariation for cardiovascular risk factors in adults. The Victorian Family Heart Study. Am J Epidemiol 2000;152:704-715.

34. Knuiman MW, Divitini ML, Welborn TA, Bartholomew HC. Familial correlations, cohabitation effects, and heritability for cardiovascular risk factors. Ann Epidemio 1996;6:188-194.

35. Khaw KT, Barrett-Connor E. Family history of stroke as an independent predictor of ischemic heart disease in men and stroke in women. Am J Epidemiol 1986;123:59-66.

36. Vitullo F, Marchioli R, DiMascio R, Cavasinni L, et al. Family history and socioeconomic factors as predictors of myocardial infarction, unstable angina and stroke in an Italian population. PROGETTO 3A Investigators. Eur J Epidemiol 1996;12:177-185.

37. Wannamethee SG, Shaper AG, Ebrahim S. History of parental death from stroke or heart trouble and the risk of stroke in middle-aged men. Stroke 1996;27:14921498.

38. Fornage M, Lopez DS, Roseman JM, Siscovick DS, et al. Parental history of stroke and myocardial infarction predicts coronary artery calcification: The Coronary Artery Risk Development in Young Adults (CARDIA) study. Eur J Cardiovasc Prev Rehab 2004;11:421-426.

39. Erbey JR, Becker DJ, Kuller LH, Orchard TJ. The association between a family history of type 2 diabetes and coronary artery disease in a type 1 diabetes population. Diabetes Care 1998;21:610-614.

40. Lee WL, Cheung AM, Cape D, Zinman B. Impact of diabetes on coronary artery disease in women and men. Diabetes Care 2000;23:962-968.

41. Juutilainen A, Kortelainen S, Lehto S, Rönnemaa T, et al. Gender difference in the impact of type 2 diabetes on coronary heart disease risk. Diabetes Care 2004;27: 2898-2904.

42. Nelson TL, Vogler GP, Pedersen NL, Hong Y, et al. Genetic and environmental influences on body fat distribution, fasting insulin levels and CVD: are the influences shared? Twin Res 2000;3:43-50.

43. Hoff JA, Daviglus ML, Chomka EV, Krainik AJ, et al. Conventional coronary artery disease risk factors and coronary artery calcium detected by electron beam tomography in 30,908 healthy individuals. Ann Epidemiol 2003;13:163-169.

44. Bensen JT, Liese AD, Rushing JT, Province M, et al. Accuracy of case reported family history: The NHLBI Family Heart Study (FHS). Genet Epidemiol 1999;17:141-150.

45. Kee F, Tiret L, Robo JY, Nicaud V, et al. Reliability of reported family history of myocardial infarction. BMJ 1993;307:1528-1530.

46. Hastrup JL, Hotchkiss AP, Johnson CA. Accuracy of knowledge of family history of cardiovascular disorders. Health Psychol 1985;4:291-306.

47. Murabito JM, Nam B-H, D'Agostino Lloyd-Jones DM, et al. Accuracy of offspring reports of parental cardiovascular disease history: the Framingham Offspring Study. Ann Intern Med 2004;140:434-440.

48. Ziogas A, Anton-Culver H. Validation of family history data in cancer family registries. Am J Prev Med 2003;24:190-198.

49. Love RR, Evans AM, Josten DM. The accuracy of patient reports of a family history of cancer. J Chronic Dis 1985;38:289-293.

50. Green J, Richards M, Murton F, Statham H, et al. Family communication and genetic counseling: the case of hereditary breast and ovarian cancer. J Genet Couns 1997;6:45-60.

51. Tinley ST, Lynch HT. Integration of family history and medical management of patients with hereditary cancers. Cancer 1999;86:1705-1712.

52. Tavani A, Augustin L, Bosetti C, Giordano L, et al. Influence of selected lifestyle factors on risk of acute myocardial infarction in subjects with familial predisposition for the disease. Prev Med 2004;38:468-472. 